\title{
Turismo comunitário a partir de experiências brasileiras, chilenas e costarriquenha
}

\section{Community tourism experiences from brazilian, chilenas and costa rican}

\section{Experiencias comunitarias de turismo brasileño, chilenas, y de costa rica}

\author{
Carlos Alberto Cioce Sampaio ${ }^{1}$ \\ Talita Zechner ${ }^{2}$ \\ Christian Henríquez ${ }^{3}$ \\ Luzia Neide Menezes Coriolano ${ }^{4}$ \\ Soraia Fernandes ${ }^{5}$
}

\begin{abstract}
Resumo: O turismo comunitário é uma estratégia para que populações tradicionais, independente do grau de descaracterização frente à hegemonia das sociedades urbanas industriais, sejam protagonistas de seus modos de vida próprios, tornando-se uma alternativa possível ao modo de vida materialista-consumista. 0 objetivo deste artigo é refinar ou, melhor, justificar o conceito de turismo comunitário a partir de experiências latinoamericanas. Estas, por sua vez, se enquadram num contexto de desvantagens históricas, principalmente de populações tradicionais. Como resultado da pesquisa, essas experimentações não se resumem em uma nova alternativa heterodoxa de turismo, e sim de experimentações que possibilitam pensar uma nova economia, ou seja, a ecossocioeconomia, por via de uma outra racionalidade e que vem acontecendo nos domicílios, nos grupos produtivos e nas comunidades, onde os problemas e suas soluções acontecem, e raramente são devidamente qualificados. Conclui-se que o turismo comunitário é uma teoria pensada a partir das experimentações, das complexidades do cotidiano, das contradições inerentes à mudança paradigmática que se deseja quando se pensa nas limitações do utilitarismo econômico e que, muitas vezes, não se dá infelizmente na velocidade que se deseja. O desafio se coloca, como preservar a lógica comunitária dessas experiências de turismo comunitário sem perder sua dinâmica própria na ocasião que se inserem na economia de mercado.
\end{abstract}

Palavras-Chaves: Turismo Comunitário; Ecossocioeconomia; Experiências Brasileiras; Experiências Chilenas; Experiência Costarriquenha.

Abstract: CT is a strategy for traditional populations to lead their own lifestyles, independently of their degree of deculturalization in the face of the industrial urban societies hegemony and, therefore, it consists

1 Professor do Departamento de Turismo e do Programa de Pós-Graduação (PPG) em Meio Ambiente e Desenvolvimento da Universidade Federal do Paraná (UFPR) e do PPG em Desenvolvimento Regional da Universidade Regional de Blumenau (FURB).

Pesquisador CNPq. E-mail: carlos.cioce@gmail.com

2 E-mail: talita.zechner@gmail.com

E-mail: christianhen@gmail.com

E-mail: luzianeidecoriolano@gmail.com

E-mail: soraia.ff.fernandes@gmail.com 
in an alternative to the consumer-materialistic lifestyle. Based on Latin American experiences, the objective of this article is to refine, or, even better, to justify the concept CT. Populations involved in these experiences, especially traditional ones, have a context of historical disadvantages. These experiences are not resumed to a new heterodox tourism alternative although they allow one to think about a new economy, the ecosocioeconomy, through a new rationality, which has been happening in domiciles, productive groups and communities, where problems and solutions occur and rarely are properly qualified. It is concluded that CT is a theory conceived from the experiences, the everyday complexities, the contradictions inherent to the pragmatic change pursued in the face of the economic utilitarianism limitations, although its implementation, many times, does not happen at the desired pace. The challenge is to preserve the communitarian logic of these experiences, without, at the same time, losing the communities' own dynamics as these get inserted into the market.

Keywords: Communitarian Tourism; Ecosocioeconomics; Chilean Experiences; Brazilian Experiences; Costa Rican Experiences

Resumen: El turismo comunitario es una estrategia para las poblaciones tradicionales, sin importar el grado de distorsión delante de la hegemonía de sociedades industriales urbanas, son los protagonistas de sus propios estilos de vida, lo que es una alternativa posible a la forma de vida materialista, consumista. El propósito de esto artículo es justificar y refinar más bien el concepto de turismo comunitario de las experiencias de América Latina. Estos, a su vez, están comprendidos en el contexto de desventajas históricas, poblaciones principalmente tradicionales. Como resultado de la investigación, estos ensayos no se resumen en un turismo alternativo heterodoxo nuevo, pero piensa en los experimentos que permiten a una nueva economía, es decir, el ecossocioeconomía, a través de otra racionalidad y lo que ocurre en casa, en grupos productivos y de las comunidades, donde los problemas y sus soluciones pasan, y están calificados en pocas ocasiones. Se concluye que el turismo comunitario es una teoría diseñada a partir de los ensayos, las complejidades de la vida cotidiana, las contradicciones inherentes al cambio de paradigma que se desea cuando se consideran las limitaciones del utilitarismo económico, y que a menudo no ocurre desgraciadamente en la velocidad que desee. El desafío se plantea, cómo preservar la lógica de estos experimentos turismo comunitario comunitario sin perder su propia dinámica en la ocasión que se incluya en la economía de mercado.

Palabras clave: turismo comunitario; Ecossocioeconomia; Experiencias brasileñas; Experiencias chilenas; experiencia de Costa Rica.

\section{INTRODUÇÃO}

O turismo comunitário ou turismo de base comunitária, em um primeiro momento, surge como tema de diálogo científico no Brasil a partir do I Encontro Nacional de Turismo de Base Local (ENTBL), realizado em São Paulo, em 1997. Em um segundo momento, adiciona-se ao debate científico a participação de movimentos sociais na ocasião do I Seminário Internacional de Turismo Sustentável, realizado em Fortaleza, 2003. Parte-se do pressuposto de que a denominação turismo comunitário é derivada de modalidades do turismo, conhecidas pelos termos turismo cultural ou etnoturismo, ecoturismo e agroturismo, como é explorado na fundamentação teórica que se apresenta. Todavia, o que caracteriza o turismo comunitário é que os empreendedores são pessoas que se inspiram por ideais comunitários, neste caso populações tradicionais, se afastando da lógica racional econômica de ganho puramente individual.

O turismo comunitário é uma estratégia para que populações tradicionais, independente do grau de descaracterização frente à hegemonia das sociedades urbanas industriais, sejam protagonistas de seus modos 
de vida próprios, tornando-se uma alternativa possível ao modo de vida materialista-consumista, Sampaio (2005).

O turismo comunitário vale-se da vitrine que representa o setor de turismo atualmente, o que significa que ele se apropria da racionalidade instrumental, mas privilegiando ganhos coletivos, como sugere $o$ enfoque da ecossocioeconomia. Saber conviver com esta lógica antagônica é apreender a conviver com a tolerância a outros modos de vidas, o que não significa necessariamente compartilhar da mesma racionalidade.

O objetivo deste artigo é refinar ou, melhor, justificar o conceito de turismo comunitário proposto por Sampaio (2005), a partir de experiências brasileiras, chilenas e costarriquenha. O conceito de turismo comunitário apresentado tem duas motivações norteadoras. A primeira é de superar a mera crítica que se faz à lógica economicista dominante do turismo, representada pelo seu estereotipo turismo de massa, apresentando uma alternativa real. A segunda é apresentar um conceito substantivo, com vida própria, um campo de conhecimento novo, transdisciplinar, distanciando-se da retórica de se tratar de mais uma modalidade de atividade turística, aprisionado na vertente econômica. Diga-se, desde já, que também não se desmerece a importância da geração de trabalho e renda ocasionada pela atividade turística, mas ela por si só não representa a densidade que o conceito turismo comunitário carrega.

Neste trabalho, se tem uma terceira motivação que é de ajustar um conceito teórico, embora tenha surgido de uma experimentação vivida, da Zona Laboratório de Educação para o Ecodesenvolvimento da Lagoa de Ibiraquera (Imbituba e Garopaba, Santa Catarina, Brasil), desde 2001, e de demais experimentações. Estas experimentações não se resumem em uma nova alternativa heterodoxa de turismo, e sim de experimentações que possibilitam pensar uma nova economia, ou seja, a ecossocioeconomia. Ela se dá no mundo da vida, por via de uma outra racionalidade, nas comunidades, nas organizações, nos domicílios, onde os problemas e suas soluções acontecem, e raramente são devidamente qualificados. É uma teoria pensada a partir das experimentações, das complexidades do cotidiano ${ }^{6}$, das contradições inerentes à mudança paradigmática que se deseja quando se pensa nas limitações do utilitarismo economicista e que, muitas vezes, não se dá infelizmente na velocidade que se deseja.

\section{METODOLOGIA}

Este artigo é uma mescla entre pesquisa bibliográfica e pesquisa formativa, sendo que esta última originou de um banco de experiências, coletadas desde 2002, contendo elementos do que pode ser apontado como características do turismo comunitário. Este banco de dados foi constituído por uma equipe de professores, pesquisadores e estudantes de graduação e pós-graduação brasileiros e chilenos da Universidade Regional de Blumenau, Universidade Federal do Paraná, Universidade Austral do Chile e Instituto de Gestão de Organizações que promovem o Ecodesenvolvimento (LaGOE, ONG brasileira).

O banco de dados surge de lições apreendidas a partir de experimentações vividas no Brasil, Chile e Costa Rica, valendo-se de pesquisa exploratória, estudo de caso e comparativo, e também pesquisa-ação. Entre elas, destacam-se onze projetos demonstrativos, cujos dados foram coletados entre 2005 e 2010: oito brasileiros - Prainha do Canto Verde (município de Beberibe, Ceará), Projeto Sana Ambiental (Macaé, Rio de Janeiro), Ecoturismo Comunitário na Amazônia Brasileira: Pousada Aldeia dos Lagos (Silves, Amazônia), Ação Ecológica Guaporé (Ecoporé): Pousada Pedras Negras (Curralinho, Rondônia), Reserva de Desenvolvimento

\footnotetext{
${ }^{6}$ Sachs $(1986 a, 1986 b)$ sugere uma enciclopédia do cotidiano.
} 
Sustentável Mamirauá (Tefé, Amazonas), Grupo Calumbé (Comunidade de Lençóis, Chapada Diamantina, Bahia) e a Associação Acolhida na Colônia (sede Santa Rosa do Sul, Santa Catarina); três chilenos - Rede de Agroturismo em Chiloé (X Região), Rede de Turismo Rural Licanhuasi (sede San Pedro de Atacama, II Região) e Rede de Parques Comunitários Mapu Lahual (San Juan de la Costa, X Região); e um costarriquenho Consórcio Cooperativo Red Ecoturística Nacional - COOPRENA (Parque Nacional Manuel Antonio, Costa Rica).

Nesta pesquisa se privilegia comparativamente os seguintes itens do banco de dados: gênese, ações implementadas, analisando seus pontos fortes e fracos, e, ainda, seus impactos gerados.

\section{REPENSANDO UMA NOVA RACIONALIDADE: ECOSSOCIOECONOMIA}

A ecossocioeconomia ${ }^{7}$ está imbricada na discussão sobre a problemática ambiental. Quando se prospecta os próximos 50 ou 100 anos de nossa economia, baseando-se no último relatório do Intergovernmental Panel of Climate Change (IPCC), divulgado em 2007, formulado pela World Meteorological Organization, WMO, no âmbito do United Nations Environmental Programme, UNEP, mesmo os mais céticos não conseguem mais ficar indiferente a tais prognósticos. Este relatório revela que a mudança climática em curso tem como principal causa à ação antrópica, sobretudo após a revolução industrial, inspirado sob a lógica racional que privilegiam resultados econômicos de curto prazo e socializam prejuízos socioambientais de médio e longo prazo, WMO-UNEP (2007).

No entanto, as respostas a tal problemática estão sendo pouco ambiciosas. A chamada ecoeficiência tenta incorporar o discurso ambiental no management, exemplificado pelo princípio poluidor-pagador, protelando uma racionalidade econômica que não dá mais conta dos desafios a serem superados, Alier (2007). Isto é, constata-se que o planeta não tem mais capacidade de absorção ou regeneração dos impactos produzidos pela ação humana (gases efeitos estufas), o que vai provocar uma mudança significativa nos modos de vida que se convencionaram a chamar de moderno (sociedade urbana industrial) ou, para os mais futuristas, pós-moderno WMO-UNEP (2007).

Associa-se neste contexto, a desigualdade social revelada pelos Indicadores de Desenvolvimento Humano, IDH, PNUD (2011) nas quais ao redor de trinta por cento da população mundial (IDH - muito elevado e elevado) possuem PIB per capita ao redor de dezessete vezes maior do que setenta por cento da população.

Este quadro mundial de tamanha desigualdade não difere proporcionalmente da realidade brasileira, chilena e costarriquenha. Não seria o momento para iniciar uma reflexão? Que lógica ou racionalidade é esta que está por trás da ação social que gera tamanhos impactos socioambientais? Um dia esta riqueza concentrada será finalmente redistribuída? O que deverá acontecer para que ela finalmente se inicie? À custa de uma tragédia colossal como inundações nas áreas costeiras provocadas por furações, de um grande incêndio provocado por falta de umidade na atmosfera e temperaturas elevadas ou de mortes provocadas por suicidas fanáticos ou terroristas que encontram uma lógica própria compensatória a um sistema que lhe parecem injusto?

7 O termo surge a partir da obra do economista ecológico Karl William Kapp (The social costs of business enterprise. Nottingham: Spokesman Books, 1963). O primeiro prefixo "Eco" (Oikos = Casa) refere-se à ecologia e reforça o que o segundo prefixo "eco" já deveria fazê-lo, contudo, este foi vulgarizado ao longo da história remetendo o seu significado ao que Aristóteles já denunciava como crematistica. 
Por sua vez, o que se convencionou a chamar de desenvolvimento econômico, sob tais argumentos, não seria difícil de redenominá-lo como mau desenvolvimento.

\section{TURISMO COMUNITÁRIO}

O turismo comunitário é uma estratégia de comunicação social para que comunidades ${ }^{8}$ tradicionais, com desvantagens históricas, viabilizem seus respectivos modos de vida. As comunidades tradicionais se definem por critérios geográficos - como um território isolado -, culturais - compartilhando costumes, usos e tradições, e feixes de hábitos -, ou por funções socioeconômicas - variando por modos de produção e distribuição, Barreto (2004) e Geertz (1989). Comunidades e seus modos de vida se confundem, entre elas, extrativistas $^{9}$, pesqueiras artesanais $^{10}$, jangadeiros ${ }^{11}$, ribeirinhos ${ }^{12}$, pequenos agricultores familiares ${ }^{13}$, faxinalenses ${ }^{14}$, indígenas, quilombolas ${ }^{15}$, caiçaras $^{16}$ e tantas outras. Tais comunidades mesmo que ainda possuam grau de descaracterização, frente à hegemonia das sociedades urbanas industriais, são identificadas como sendo tradicionais. O que possibilita encontrar no seu âmbito o principal atrativo do turismo, a convivencialidade, de inspiração comunitária. Característica esta que se tornou exótica no âmbito do modo de vida material-consumista.

Convivencialidade é uma relação social que se interessa pelo outro, pelo diferente, pela alteridade, pela autenticidade, respeitando a simplicidade das comunidades tradicionais, suas rotinas, seus jeitos de falar, cantar, dançar, comer, entre outros. Na sua essência supera a mera relação de negócio, possibilitando resgatar e reconstruir a interconectividade entre modos de vida distintos (congregando tipos de conhecimento - formal com tradicional - e culturas - ocidentalizadas com tradicionais) e entre sistemas sociais e ecológicos, Illich (1976), Irving \& Azevedo (2002), Coriolano \& Lima (2003), Sampaio (2004, 2005), Sampaio (2010).

${ }^{8}$ As comunidades são grupos sociais que compartilham um legado cultural e histórico, e habitam um território compartilhando problemas e de suas soluções (HOUAISS e VILLAR, 2001). A vida comunitária entre os homens requer a existência de crenças morais compartilhadas e de normas publicamente aceitas, demarcando a conduta lícita e ilícita (FONSECA, 1993, p. 65).

9 Os extrativistas se utilizam do manejo da biodiversidade vegetal - cipós, fibras e ervas medicinais da floresta, e animal - caça e pesca (DIEGUES, 2000).

10 Os pescadores artesanais estão inclusos na categoria extrativismo animal, contudo se diferenciam por habitarem em zonas costeiras e ribeirinhas.

11 Os jangadeiros estão inclusos na categoria extrativismo animal, contudo se diferenciam por habitarem em zonas costeiras do Nordeste.

12 Os ribeirinhos estão inclusos na categoria extrativismo animal e vegetal, contudo se diferenciam por habitarem as margens (ribeiras) dos rios, sobretudo no Norte do Brasil.

${ }^{13}$ Os pequenos agricultores familiares se caracterizam, sobretudo, pela agricultura de subsistência e vivem nas zonas rurais.

14 Os faxinalenses são comunidades de pequenos agricultores familiares que possuem áreas comunais de criação pecuária e de proteção ambiental no Paraná.

15 Os quilombolas são grupos de afro-descendentes, de origem considerada cujos antepassados historicamente se refugiaram nas florestas para escapar do antigo regime escravocrata ou de seus resquícios, que se tornaram camponeses e possuidores de terra (GUANAES, LIMA \& PORTILHO In: DIEGUES, 2004).

16 Os caiçaras são frutos da miscigenação entre índio, português e negro (em menor quantidade) que durante longo período ficaram relativamente isolados na Mata Atlântica e no litoral de São Paulo. Eles vivem por meio da caça de subsistência, agricultura itinerante, do extrativismo vegetal - palmito e cacheta - e da pesca artesanal (DIEGUES, 2000, p. 140). 
Nesta ambiguidade entre comunidades e seus modos de vida se encontra o conceito de território que pode ser definido como um espaço concreto da natureza no qual uma sociedade determinada reivindica e garante aos membros a possibilidade de direitos estáveis de acesso e uso sobre a totalidade ou parte da biodiversidade existente que nela deseja ou é capaz de utilizar, Godelier Apud Diegues (2000). Diegues (2000) complementa que o território fornece os meios de subsistência e de produção e, ao mesmo tempo, cria uma dinâmica social que o diferencia - seus modos de vida próprios -, tanto quanto seus aspectos físicos que o limitam. O território é também o locus dos sistemas de representações, identidades, símbolos e mitos que as populações tradicionais constroem, pois é com base nele que agem sobre o meio ambiente em que vivem. 0 imaginário popular das populações tradicionais encontra mecanismos próprios de conservação da biodiversidade, podendo determinar lugares da floresta e determinadas espécies de fauna e flora como sagrados, restringindo assim áreas de visitação ao turismo.

O turismo comunitário oportuniza que visitantes conscientes - estudantes, professores, pesquisadores e simpatizantes - tomem contato com temas relacionados à preservação da natureza (sistemas ecológicos) e, ao mesmo tempo, a conservação de modos de vida tradicionais (sistemas sociais). Além da convivencialidade, outro atrativo é o de vivenciar a dimensão espaço-tempo regulada pelo sol, pela lua e pelas chuvas, enfim, pelas estações do ano. Tais experiências vêm sendo organizadas e viabilizadas por Organizações Não-Governamentais (OnGs), tais como o Instituto LaGOE (com sede em Curitiba, Paraná) e AGRECO (sede em Santa Rosa de Lima, Santa Catarina), a baixo custo, gerando trabalho e renda local e sendo monitorados como zonas laboratórios, constituindo redes de ajuda que articulam esforços para atenderem as demandas comunitárias e que, ao mesmo tempo, estreitam laços entre os próprios visitantes, McGehee (2002); Sampaio et al.(2007). Há de destacar que o contato com os visitantes estrangeiros fortalece ainda mais os laços com a população visitada, o que contribui para que os encontros interpessoais minimizem ou desfaçam preconceitos entre as partes em contato, Pearce In: Theobald (2002).

Quando se referem às comunidades, sobretudo as tradicionais, sabe-se que essas populações na sua grande maioria estão descaracterizadas culturalmente em diferentes graus. Entretanto, o que importa é a identidade cultural que se quer resgatar das comunidades tradicionais ou o pouco que delas se desejam conservar. Contudo, as populações autóctones não são influenciadas de maneira unilateral e passiva pelos visitantes (turistas), isto é, como que as comunidades tradicionais também não os influenciassem. $O$ turismo pode ser também potencializador do resgate de aspectos étnicos, sem necessariamente espetacularizar a autenticidade dessas culturas Pagdin (1995), Grünewald ( 2002), Barretto (2004), Kim (2006). Por consequência, a autenticidade não é um conceito fechado em si mesmo, ele é negociável em seu significado. Da mesma maneira, as culturas tradicionais não são estáticas, estão em constante mudança seja por fatores endógenos ou exógenos, Greenwood (1982), Cohen (1988), Nash (1996), Diegues (2000). A questão que se apresenta é como equacionar melhor as vantagens das atividades do turismo em uma comunidade sem deixá-la (a comunidade) com os problemas geralmente encontrados pelo turismo de massa: ociosidade de mão de obra local durante a maior parte do ano, elevação anormal de preços, especulação imobiliária, segregação entre nativos e visitantes, trânsito, violência (consumo de drogas), prostituição e vulgarização da autenticidade, Mercer In: Theobald (2002). Surgem, então, modalidades menos evasivas, contudo que não devam ser confundidas com o turismo comunitário, turismo cultural ou etnoturismo (incluindo o turismo indígena), ecoturismo e agroturismo.

O turismo cultural se volta para a observação ou convívio de estilos de vida tradicionais, Barreto (2004). Mesmo podendo ser considerado como turismo cultural, o turismo indígena se restringe a observação ou convívio com povos de nações minoritárias sujeitadas às histórias coloniais, mas com direitos que 
preservam sua autonomia, ILO (1991). O turismo cultural com facilidade acaba sendo mais um produto turístico comercializado por consequência da produção cultural do mercado - ou melhor, das empresas que se interessam produzir ou realçar determinado traço cultural -, e no melhor dos casos do fomento governamental em políticas de revitalização cultural. Assim, há de se atentar quanto ao risco tanto de exotização ou espetacularização dos modos de vida tradicionais como que fossem meras mercadorias, exemplificado pela comercialização da imagem do povo Maori (Nova Zelândia) como que fossem grandes guerreiros, Garrod \& Fyall (1998), Ryan (2002). Por outro lado, há um grande potencial quando se trata de atrações turísticas culturais, exemplificadas em quatro conjuntos: festivais e atrações musicais; parques comerciais de recreação; festividades e feiras locais; e eventos relacionados à procura de conhecimento e estética.

Embora se tenha oitenta e cinco definições de ecoturismo ${ }^{17}$, o termo atualmente está vulgarizado, sobretudo, quando esta modalidade de turismo é apropriada pela lógica econômica, como exemplificado na desapropriação de terras comunitárias por um megaempreendimento que se intitula resort ecológico. Se ainda não bastasse, acaba cercando a praia e não possibilitando nem se quer o trânsito de pedestres que ali passavam por gerações. Para que possa ser chamado como ecoturismo, Blamey $(1997,2001)$ sugere satisfazer três critérios. Primeiro, os atrativos deveriam ser predominante baseados na natureza; segundo, a interação dos visitantes com esses atrativos deveriam ser inspirados sob um enfoque educativo. Combinando estes dois primeiros critérios, exemplifica-se o ecoturismo vinculado a áreas públicas protegidas e, também, na crescente oferta do ecoturismo em áreas privadas protegidas, sobretudo na América Central (especialmente na Costa Rica), Brasil e África, Weaver \& Laton (2007). Terceiro, o produto ecoturístico deveria seguir princípios e práticas associados à sustentabilidade ecológica, sociocultural e econômica. Para Scheyvens (1999), a principal motivação para viagem relacionada ao tema do ecoturismo é o desejo de ver ecossistemas em seu estado natural, sua vida selvagem assim como sua população nativa. Para Laarman e Durst (1987) o ecoturismo, como produto turístico, pode ser classificado entre soft e hard ecoturismo. O soft ecoturismo é associado com serviços e facilidades de alto padrão, mediando o encontro entre visitantes e o espaço natural no qual se respeita a capacidade de carga dos ecossistemas. Enquanto que o hard ecoturismo se relaciona com serviços e facilidades de padrão do que se conhece por ecohostel (hospedarias), como se vê em experiências que vão à direção do turismo comunitário.

O Agroturismo refere-se a um conjunto de serviços requeridos por visitantes e turistas que desejam adquirir a experiência de conhecer a vida de uma pequena propriedade rural, Schaerer \& Dirven (2001), Oyarzún \& Carcamo (2001; Hernandez Maestro Et Al. (2007). As atividades turísticas são realizadas em áreas rurais e há uma predominância de estadias curtas provocada por ausência de roteiros turísticos. A dificuldade de roteirização entre as propriedades, no caso latino americano, muitas vezes se dá pelas distâncias e a má conservação das estradas de terra, além de muitas propriedades oferecerem serviços muito parecidos, carecendo de atrativos mais criativos como, por exemplo, de um museu paleontológico de propriedade de um agricultor ofertado na llha de Chiloé (Chile) ou da chamada feira viva que comercializa produtos in natura ou agroindustrializados oferecida na Estrada Bonita, em Joinville, e na Acolhida na Colônia, com sede em Santa Rosa de Lima, ambas em Santa Catarina. Além do mais, o produto agroturismo possui dificuldade de comercialização, carecendo de agencias de turismo especializada, quadro este não muito diferente para os produtos ecoturismo e turismo cultural, e até mesmo para o turismo comunitário Sampaio et al. (2007; 2005).

17 Fennell Apud Weaver e Laton (2007) identifica 85 definições de ecoturismo e seus valores estão baseados tais como conservação, ética, sustentabilidade, educação e benefícios comunitários. 
Embora o turismo comunitário tenha como eixo norteador integrar vivências, serviços de hospedagem e de alimentação, o que a priori não o diferencia das três modalidades de turismo apontadas anteriormente, uma primeira característica que o diferencia é entender a atividade turística como um subsistema interconectado a outros subsistemas, como educação, saúde e meio ambiente. Ou seja, o turismo comunitário é pensado como um projeto de desenvolvimento territorial sistêmico (sustentável) a partir da própria comunidade, o que poderia ser destacado como segunda característica. Irving e Azevedo (2002) se referem ao turismo comunitário como "turismo sustentável", onde para ela, o desenvolvimento desta atividade exige a incorporação de princípios e valores éticos, uma nova forma de pensar a democratização de oportunidades e benefícios, e um novo modelo de implementação de projetos, centrado em parceria, coresponsabilidade e participação. A terceira característica é a convivencialidade entre população originária residente (inclusive, não descartando os domiciliados não residentes, isto é, migrantes) e visitantes, incrustada em um arranjo socioprodutivo de base comunitária, fomentando redes de encadeamentos produtivos que se vale de arranjos institucionais, nos quais os próprios visitantes contribuem para seu fomento, como acontece na experiência da Microbacia do Rio Sagrado (Morrestes, Paraná) quando se constituem vivências comunitárias que relacionam uma cozinha comunitária que agroindustrializa produtos, uma associação de artesãos entre os quais produzem a partir da fibra da bananeira ou do cipó imbé, um socioempreendedor que fabrica artesanalmente cachaça e licores e outro que manipula ervas naturais, e uma feira de troca solidárias que reúne moradores das comunidades, Coriolano \& Lima (2003), Sampaio (2004), Sampaio Et Al. (2006).

A convivencialidade potencializa espaços produtivos (não necessariamente visando comercialização) de ganho coletivo e que podem ser chamados de ecossocioeconômicos, como, por exemplo, clubes ou feiras de trocas solidárias e as plataformas de comércio justo. O comércio justo surge para assegurar uma nova relação, livre, direta e honesta entre três novos sujeitos econômicos: produtores em vias de empobrecimento, geralmente excluídos ou com desvantagens no comércio praticado no âmbito da economia de mercado; consumidores solidários que estão dispostos a pagar um sobrepreço; e os intermediários sem ânimo de lucro. Nesta relação existe a perspectiva de contratos em longo prazo, baseados no respeito mútuo, de maneira que permita ao produtor e sua família viver mais dignamente, Plataforma Komyuniti (2005), Espanica (2005). O Clube de Troca Solidária mediado ou não por uma moeda social tenta reconstruir o vínculo social entre produtores e consumidores, denominado por Lisboa e Faustino (2006), enquanto prossumidores, através da convivência e de laços de solidariedade. Quando não é possível o escambo de bens e serviços, valese de uma moeda social para facilitar a troca entre os sócios do clube.

\section{EXPERIÊNCIAS QUE VÃO AO ENCONTRO À ECOSSOCIOECONOMIA E AO TURISMO COMUNITÁRIO}

As experiências que podem ser consideradas de turismo comunitário vêm chamando atenção, mesmo ainda não tendo esta intenção, sobretudo pela capacidade potencial de municípios latino-americanos de implementarem uma atividade econômica de baixo investimento (de pequena escala), geradora de postos de trabalhos não especializados e de baixo impacto ambiental. Contudo, há poucas comunidades que vêm demonstrando capacidade de associativismo articulado, chamado por arranjo socioprodutivo de base comunitária, na América Latina. Entre elas destacam-se onze projetos demonstrativos em curso brevemente apresentados a seguir.

\subsection{Prainha do Canto Verde (município de Beberibe, Ceará)}


Um dos casos mais conhecidos e estudados de turismo comunitário brasileiro é a Prainha de Canto Verde, situada no município de Beberibe, no litoral do Ceará. O planejamento da atividade turística na localidade teve início em 1994 através da construção do Projeto Turístico Socialmente Responsável. Uma das preocupações centrais do projeto era, e é até hoje, desenvolver a atividade valendo-se do planejamento participativo e descentralizado. O turismo passou a ser discutido nas reuniões da Associação de Moradores e verificou-se que a comunidade percebia a geração de trabalho e renda como um dos principais benefícios a serem trazidos pelo turismo, caso começasse a ser implantado na localidade. Os autóctones entendiam que a atividade turística deveria ser organizada e realizada por eles, para que não existisse uma exploração inadequada por grandes organizações externas. Entre as principais ações implantadas na localidade, pode-se mencionar a criação do Conselho de Turismo, a organização da COOPECANTUR (Cooperativa de Turismo), realização de seminários e cursos para a comunidade, realização do Projeto Artescola que tem como objetivo implementar o empreendedorismo e reciclar materiais da localidade, consolidação do Projeto Estaleiro Escola, concretização do Projeto SODIS (trata-se de um método simples e de baixo custo que serve para desinfetar a água a nível doméstico), realização do Projeto Agroecologia que se baseia nos princípios ecológicos de sustentabilidade e nos saberes da comunidade e a efetivação do Projeto Canto Verde Digital (inclusão digital). Tais atividades apresentam como pontos fortes a geração de trabalho e renda, a ampliação da venda de peixes e lagostas, a valorização do artesanato local, a melhoria da educação, do sistema de saúde e da infraestrutura básica como energia e água encanada. Existem alguns pontos fracos, como o aumento do custo de vida e a escassez de espaço para a construção de moradias para as gerações futuras das comunidades. Pode-se afirmar que os principais impactos que ocorreram depois da implantação do projeto foram a melhoria da qualidade de vida dos membros comunitários, o aumento da autoestima dos autóctones, a geração de trabalho e renda para os moradores, o fortalecimento da cultura associativa e o fortalecimento das lideranças comunitárias.

\subsection{Projeto Sana Ambiental (Macaé, Rio de Janeiro)}

Existiam problemas socioambientais na localidade decorrente do fluxo turístico descontrolado. Para ajudar a amenizar a problemática do local, foi elaborado o projeto Pequena Semente que objetivou desenvolver a consciência ecológica de turistas e moradores. O projeto Pequena Semente, mesmo sem recursos, alcançou ótimos resultados e tomou força originando uma organização não governamental denominada Grupo de Defesa Ecológica Pequena Semente (GDEPS), criado em fevereiro de 1995. A OnG passou a ampliar a sua atuação buscando uma maior mobilização comunitária para as questões ligadas ao planejamento e à gestão de um turismo sustentável para a região. Outro projeto implantado é o Capitão Minhoca, desenvolvido em parceria com um fazendeiro da região. Nesta ação a ONG ficou responsável por transformar a Fazenda Barra do Sana em uma Reserva Particular de Patrimônio Natural (RPPN) e o proprietário, em contrapartida, disponibilizou as instalações para que fosse desenvolvido um horto-escola. 0 principal objetivo do projeto foi recuperar áreas degradadas, além de formar agentes de plantio e produtores de mudas. Devido a esta iniciativa, foram recuperados mananciais e mata ciliar do Rio Sana e seus afluentes com o replantio de mais de 300 mil árvores. Em Sana acontece ainda o projeto Criança Semente, que desenvolve oficinas de sensibilização e educação ambiental para as crianças. Como é comum acontecer no Brasil, uma das maiores dificuldades para manter os projetos na localidade é a limitação de recursos financeiros e na localidade de Sana, para minimizar esta situação foi criado pelo GDEPS um selo de 
"Estabelecimentos Verdes". Conforme relatado no formulário, todos os estabelecimentos comerciais, pousadas, campings e associações que contribuem de alguma forma para a manutenção dos projetos em andamento, recebem um selo e são incluídos em um folder distribuído aos turistas. Para monitorar as cachoeiras que existem na localidade, consideradas um importante atrativo turístico a ONG GDEPS dispõe do projeto "Nossa Casa, Nossa Terra" que também se preocupa com a educação ambiental. Atualmente o GDEPS em parceria com o Instituto de Psicologia da UFRJ, mantém o Projeto Sana Sustentável que tem como objetivo central estimular os atores sociais a participarem do processo de planejamento turístico da localidade.

\subsection{Ecoturismo Comunitário na Amazônia Brasileira: Pousada Aldeia dos Lagos (Silves, Amazônia)}

A experiência estudada no município de Silves, na Amazônia, trata-se de um projeto de Ecoturismo Comunitário e tem como atrativo central a Pousada Aldeia dos Lagos e conta com a exuberante beleza amazônica como principal atrativo. O município de Silves possui trinta e duas comunidades ribeirinhas que dependem da pesca para sobreviver. As atividades de ecoturismo representam uma oportunidade para as comunidades e acontecem com o apoio da World Wildlife Fund (WWF). Existe uma preocupação em agir avesso a prática de qualquer atentado contra a natureza, preservando assim a biodiversidade local. Em 1993 teve início o projeto da Associação de Silves pela Preservação Ambiental e Cultural (ASPAC) que formalizou-se através de uma organização não governamental formada por comunidades de ribeirinhos. A OnG apoiou a capacitação e organização de atividades relacionadas ao turismo que resultou na comercialização de um pacote turístico que é oferecido aos visitantes hospedados na Pousada Aldeia dos Lagos. O pacote inclui passeios e caminhadas pela região, nos quais durante o percurso o turista visita as casas dos moradores, pomares, roçados, pequenos engenhos (residências) onde se faz a farinha, e tem a oportunidade de verificar como acontece a pesca artesanal. Atualmente, a Pousada Aldeia dos Lagos é gerida pela comunidade e parte da renda obtida com o turismo é aplicada em ações para a conservação ambiental da várzea e dos lagos do município.

\subsection{Ação Ecológica Guaporé (Ecoporé): Pousada Pedras Negras (Curralinho, Rondônia)}

A Ação Ecológica Guaporé tem como empreendimento central a Pousada Pedras Negras, onde são praticadas atividades de ecoturismo que acontecem com o envolvimento da comunidade. Para coordenar as atividades desenvolvidas, entre elas, a preservação de Matas Ciliares, o manejo do pescado, o manejo florestal e o ecoturismo, Ecoporé conta com as seguintes instituições apoiadoras: Organização dos Seringueiros de Rondônia, Ação Ecológica Guaporé ECOPORÉ), Ação ao Manejo Florestal na Amazônia e Programa para o Desenvolvimento do Ecoturismo da Amazônia Legal. As atividades tiveram início em 1988 e contribuíram para a melhora das condições de vida da comunidade local, sobretudo das mulheres, aumento da renda das famílias e minimização dos impactos ambientais. Nesta experiência, os turistas têm a oportunidade de conhecer as tradições e costumes dos autóctones e experimentar um pouco da vida na floresta. Na vila das Pedras Negras onde está localizada a pousada, vivem 18 famílias, que propiciam as atividades de turismo, que incluem ainda a extração da castanha (entre os meses de janeiro e abril), a extração do látex da seringueira, a confecção da farinha de mandioca e a pesca tradicional. Atualmente, uma das principais dificuldades encontradas para a manutenção dos projetos é a limitação de recursos financeiros. 


\subsection{Reserva de Desenvolvimento Sustentável Mamirauá (Tefé, Amazonas)}

O Instituto de Desenvolvimento Sustentável Mamiruá (IDSM) objetiva proteger uma grande área de floresta tropical, através do manejo comunitário. O instituto foi criado em 1999 e desenvolve alguns programas como o de Qualidade de Vida que trata da questão da adaptabilidade humana aos ecossistemas naturais e busca também o fortalecimento de ações vinculadas às políticas publicas de desenvolvimento sustentável. Este programa abrange ainda temas relacionados à educação ambiental, saúde comunitária e tecnologias apropriadas. Outro importante programa coordenado pelo IDSM é o Programa Ecoturismo, que promove uma forma sustentável de geração de trabalho e renda, utilizando mão de obra local (devidamente capacitada), venda de artesanato e compra de produtos agrícolas.

\subsection{Grupo Calumbé (Comunidade de Lençóis, Chapada Diamantina, Bahia)}

O Grupo Calumbé iniciou suas atividades após uma parceria entre o Projeto Bagagem, de São Paulo, e a OnG Grãos de Luz e Griô, de Lençóis. Tal grupo objetiva consolidar na Chapada Diamantina um núcleo, gerenciado por jovens nativos, que crie, acompanhe e avalie o Turismo de Base Comunitária na região. Diversas ações têm sido efetuadas neste sentido como as trilhas alternativas guiadas por moradores que repassam para o turista um pouco da história do local. Existem diferentes trilhas, cada qual com uma temática. O roteiro oferecido no local pretende levar ao participante a oportunidade de fazer parte da cultura sertaneja baiana do garimpo de diamantes, do samba de roda, do terno de reis, do forró pé de serra, dos raizeiros $^{18}$, parteiras e de outras tradições locais. Cabe destacar que o Grupo Calumbé desenvolve suas atividades mediante um significativo envolvimento por parte dos autóctones que já percebem no turismo uma alternativa de conservar os seus modos de vida. O grupo sofre com dificuldades de ordem financeira para manter seus projetos e conta com um apoio financeiro através do Projeto Bagagem que promove a vinda de turistas e cobrando tarifas pelas viagens.

\subsection{Associação da Acolhida na Colônia (sede Santa Rosa de Lima, Santa Catarina)}

A AGRECO inicia sua atividade nos anos 90 marcada por um trabalho associativo e baseado nos princípios da agroecologia. $O$ projeto assume importância para estudantes e pesquisadores, bem como para turistas que começam chegar para observar as atividades de agricultura agroecologica que a comunidade desenvolvia. No ano de 1999 foi fundada a Associação de Agroturismo Acolhida na Colônia em parceria com a AGRECO. Dentre as ações implementadas destacam-se adaptação de 50 propriedades rurais para o agroturismo, criação de uma central de reservas gerenciada pela comunidade, realização de vivências no meio rural, social e produtivo, baseados nos princípios da agricultura ecológica. Como pontos fortes destacam-se as estratégias de marketing aplicadas a localidade, o nível de associativismo, a colocação de produtos em novos mercados, a hospitalidade da comunidade receptora e o destaque do modo de vida tradicional. A localização geográfica dificulta o acesso, estradas mal conservadas, dificuldade de gerenciamento da central de reservas, identidade cultural fragilizada e descaracterização das moradias locais. No começo a proposta foi altamente positiva, contudo com o passar do tempo, os impactos ecossocioeconômicos começam a mostrar dificuldades de sustentabilidade do projeto.

18 


\subsection{Rede de Agroturismo em Chiloé (Região Los Lagos, Chile)}

No ano 1996 tive início o projeto que tinha como objetivo convocar e capacitar um grupo de famílias de agricultores distribuídas em todo o arquipélago de Chiloé para que, de maneira organizada, as famílias pudessem se tornar parte da oferta turística e, assim, prover desenvolvimento local e sustentável. A ideia principal foi que as famílias preparassem suas casas adequadamente para hospedarem turistas de modo que eles pudessem vivenciar os modos de vida próprios da comunidade ${ }^{19}$, participando em grande parte das tarefas tradicionais das propriedades que ficam no local. Além disso, os turistas podem desenvolver diferentes atividades como cavalgadas, participação em feiras tradicionais, conhecer como se fazem as diferentes comidas, contemplação do patrimônio natural entre outras. Chama atenção, a participação ativa do grupo familiar, o que facilita a interação com os turistas. A rede de agroturismo de Chiloé foi pioneira no Chile a trabalhar o agroturismo de maneira associativa. Como ponto fraco, aponta-se falta de financiamento para melhorar as moradias, alguns prestadores de serviços estão localmente dispersos, no verão existe dificuldade de chegar ao arquipélago de Chiloé já que o sistema de ferry boat tem grande procura, falta de coesão do grupo decorrente da amplitude geográfica da área e dificuldade das famílias de bem gerenciarem a renda proveniente da atividade turística. Como impacto, destacam-se a geração de trabalho e renda, através da venda de produtos agrícolas locais, além do artesanato, peixes, frutos do mar; melhoramento qualitativo das casas das famílias participantes e, consequentemente, na qualidade de vida dos moradores; e reconhecimento do trabalho da mulher posto que é esta a autora chave na recepção dos visitantes.

\subsection{Rede de Turismo Rural Licanhuasi (sede San Pedro de Atacama, Região Atacamenha, Chile)}

Criado em 1999 quando as comunidades membros do conselho de povos Atacameños decidem trabalhar no setor de turismo, como estratégia para revitalizar o patrimônio sociocultural e socioambiental e, ainda, complementar a renda familiar melhorando a qualidade de vida dos moradores. As atividades implantadas foram: capacitação em manejo de recursos naturais, conservação do patrimônio, implementação de serviços de hospedagem, produção gastronômica, elaboração de circuitos turísticos e formação de guias turísticos. Os pontos fortes foram: modelo de gestão associativa, criação de uma rede de empregos permanentes para moradores locais, diminuição das migrações para centros urbanos, aumento das possibilidades de desenvolvimento territorial, melhora da qualidade de vida dos moradores e conservação do patrimônio natural e cultural, chamando atenção o museu arqueológico de um sábio paleontólogo. Faltam recursos econômicos próprios para melhor competir com projetos turísticos maiores de caráter privado e de imigrantes. Como impacto foram o estabelecimento de uma fonte de trabalho permanente, melhoria da qualidade de vida, conservação da sociobiodiversidade local e consolidação de um trade turístico alternativo à oferta do chamado turismo de massa na localidade.

\subsection{Rede de Parques Comunitários Mapu Lahual ${ }^{20}$ (San Juan de la Costa, Região Los Lagos, Chile)}

\footnotetext{
${ }^{19}$ Embora se saiba que a comunidade esteja descaracterizada.
}

${ }^{20}$ Mapu Lahual quer dizer terra (mapu) das alerces (lahual) em língua indígena (Mapuche). Alerce é uma espécie de árvore milenar endêmica do sul de Chile. 
Criado em 2006, pelo governo do Chile em parceria com o Global Found Enviroment, trata-se de uma Área Marinha Costeira protegida de múltiplos usos e a única com presença de comunidades tradicionais dentro dos limites da área. $O$ objetivo da rede é a conservação da natureza e a complementação da renda comunitária. Entre as atividades realizadas, destacam-se a formação de associações indígenas e a criação de cinco novas áreas silvestres para a conservação, possibilidade de intercâmbio de conhecimentos entre as comunidades tradicionais, construção de quatro centros de educação ambiental e cinco bibliotecas temáticas e mais trilhas temáticas dedicadas à educação ambiental, e a realização de mostras culturais nas quais são apresentadas gastronomia local e manifestações tradicionais. Os pontos fortes se enumeram: área rica em sociobiodiversidade, considerada pelo governo chileno uma das áreas mais importante à conservação, e considerada pela WWF e Banco Mundial como uns dos 200 ecossistemas mundiais que ainda conservam elementos únicos. A metodologia com a qual se vem trabalhando é entendida como participativa e transdisciplinar, relevando o grau de complementaridade entre conhecimento científico e tradicional. Dois pontos se destacam: articulação entre os parques comunitários (de propriedade familiar) e a criação de centros comunitários que disponibilizam serviços básicos. O difícil acesso ao local é um dos empecilhos que dificulta a viabilidade do projeto, dificultando a chegada de visitantes às localidades. Como impacto, destacam-se a criação de um decreto legislativo que regula o acessos e usos da área (Lafken Mapu Lahual), participação na reunião das Partes da Convenção da Biodiversidade, realização de um seminário internacional e de exposições itinerantes em diferentes municípios do Chile, seis comunidades indígenas capacitadas pelo Serviço Nacional de Turismo e geração de trabalho e renda para os membros da rede.

\subsection{Consórcio Cooperativo Red Ecoturística Nacional - COOPRENA (Parque Nacional Manuel Antonio, Costa Rica)}

Nos anos 60 e 70 existia na Costa Rica uma forte luta pelos domínios de terras, existindo uma comunidade de 60 famílias que lutava por direitos de uso e acesso por uma área que havia sido abandonada por uma empresa transnacional. A comunidade tomou posse de mais 500 hectares e fundaram a COPESILENCIO, que logo no início dos trabalhos buscou novos associados e parcerias para desenvolver projetos rurais. As principais atividades realizadas foram a capacitação de famílias de agricultores, trabalho em rede e implantação do ecoturismo comunitário. Como pontos fortes destacam-se a organização social, inserção das mulheres e jovens nos projetos desenvolvidos, preservação dos recursos naturais e resgate cultural. Um dos pontos fracos é a falta de visibilidade dos serviços ecoturísticos ofertados no âmbito internacional, considerando que a Costa Rica é uma destinação internacional. Como impacto destaca-se a melhora da autoestima da comunidade, participação ativa da comunidade na preservação dos recursos naturais e a articulação comunitária em redes de trabalho que primam de modos de produção tradicional.

\section{CONCLUSÕES}

Após estudar as onze experiências que conformam o turismo comunitário, verificou-se que todas elas são recentes e que a maioria está localizada em espaços naturais, considerados Unidades de Conservação. A gênese das experiências fica atrelada a projetos de finalidade socioambiental (de caráter sistêmico) e com a 
intenção premeditada de promover a atividade turística, mesmo se identificados com as modalidades tradicionais de turismo: turismo cultural, ecoturismo e agroturismo. A iniciativa dos projetos conta quase sempre com o apoio institucional de Organizações não Governamentais ou Universidades que, aliás, não se estranha, sobretudo em democracias políticas que não são necessariamente exemplos de democracia econômica - típicas dos países da América Latina, isto é: países que apresentam problemas de redistribuição de renda e de baixa escolaridade. Então, é compreensível, ao menos em um primeiro momento, que comunidades com desigualdades históricas se aproveitem da iniciativa de instituições formalizadas e melhores articuladas com as estruturas de poder político e econômico que mantêm interlocuções com as esferas do Estado, mercado e sociedade civil organizada, de modo que possam aproveitar das benesses de uma pseudo incubação, recebendo apoio gerencial e financeiro aportadas por tais instituições.

Assim, o turismo comunitário está organizado associativamente no âmbito territorial e é quase uma condicionante no processo de planejamento e implantação do turismo comunitário a realização de reuniões e seminários junto às comunidades locais. Contudo, na maioria dos casos, o associativismo comunitário não surge como movimento espontâneo e sim como uma estratégia comunitária para enfrentar as forças da economia de mercado (para isto se organizam em cooperativas) e do Estado (se organizem em associação de moradores), o que não implica necessariamente como algo ruim como se apontou no parágrafo anterior. Mesmo porque, é notável nas experiências a falta de apoio dos governos municipais e que se tratam de comunidades afastadas das sedes de seus municípios, o que sugere certa correlação.

Conclui-se também que nos territórios que experimentam o turismo comunitário, existe uma preocupação significativa com aspectos relacionados ao patrimônio natural e cultural. Em alguns casos, acontecem de maneira paralela ou integram as experiências de turismo comunitário, cuja finalidade é de preservar a biodiversidade e conservar os modos de vida tradicionais. Não é novidade que as experiências analisadas, sob a inspiração do turismo comunitário, são implantadas em comunidades que estão localizadas distantes dos perímetros urbanos e, por isto, a acessibilidade, em um primeiro momento, possa parecer uma limitação à visitação. Por um lado, há o risco que estradas asfaltadas ou free ways acabem gerando impactos como bem fazem à modalidade turismo de massa, e por outro, acabem trazendo conforto e rapidez no transporte aos moradores locais. Contudo, acredita-se que o próprio deslocamento, com suas dificuldades implícitas, possa fazer parte do pacote turismo comunitário.

Com tais aprendizados, surgem algumas qualificações para o conceito turismo comunitário. 0 termo estratégia de comunicação social para comunidades tradicionais é utilizado propositadamente de maneira que não confunda turismo comunitário como mais uma nova tipologia de atividade econômica, tal como as muitas já existentes. Nessas experiências analisadas, importa de que maneira a geração de trabalho e renda são criadas. Elas surgem de base endógena e são produzidas no próprio território. A oferta de trabalho e renda está correlacionada com a possibilidade de se conservar seus modos de produção e as respectivas fontes de bens e serviços ambientais que, por sua vez, qualificam seus modos de vida e a biodiversidade no espaço natural. Resignifica-se a relação desenvolvimento e meio ambiente, tornando a problemática ambiental como eminentemente social.

Ao mesmo tempo, os visitantes têm a oportunidade de tomarem consciência de que existem alternativas ao modo de vida urbano material-consumista. Sob tal perspectiva, o turismo comunitário possui uma vertente educativa quando os aprendizados vivenciados servem tanto para reforçar a autoestima das comunidades receptoras, seja a partir das feiras de trocas solidárias ou do comércio justo, quanto para potencializar a superação das expectativas do visitante, sobretudo na ocasião em que a relação socioeconômica é substantiva entre visitado e visitante - distanciando-se da relação que se está acostumada 
parametrizada pela razão econômica individual (um ganha e o outro necessariamente não) -, e que possibilita vivenciar uma relação social parametrizada na convivencialidade, mesmo se ainda tenha algum caráter de relação econômica implícita.

\section{REFERÊNCIAS}

Alier, J. M. (2007). O ecologismo dos pobres. São Paulo: Contexto.

Barretto, M. (2004). Relações entre visitantes e visitados: um retrospecto dos estudos socioantropológicos. Turismo em Análise , 15 (2), pp. 133-149.

Blamey, R. (1997). Ecotourism: the search for an operational definition. Journal of Sustainable Tourism , 5 , pp.109-130.

Blamey, R. (2001). Principles of ecotourism. In D. Weaver, Encyclopedia of ecotourism. Wallingford: CAB Internactional. pp. 5-22.

Coriolano, L. N., \& Lima, L. C. (2003). Turismo comunitário e responsabilidade socioambiental. Fortaleza: EDUECE.

Diegues, A. C. (2000). O mito moderno da natureza intocada. São Paulo: Hucitec, Núcleo de Apoio à Pesquisa sobre Populações Humanas e Áreas Úmidas Brasileira. ESPANICA. El comercio justo: origen y evolución. Disponible em http://www.nodo50.org/espanica/cjust.html\#primeras. Acesso em:

20/jun/2005.FINLEY, Moses I.. A economia antiga. Porto: Edições afrontamento, 1980.

Fonseca, Eduardo Giannetti da. (1993). Vícios privados, benefícios públicos?: a ética na riqueza das nações. São Paulo: Companhia das Letras.

Garrod, Brian; Fyall, Alan. (1998). Beyond the rhetoric of sustainable tourism? Tourism Management, 19 (3), pp. 199-212.

Geertz, Clifford. (1989). A interpretação das culturas. Rio de Janeiro: LTC.

Greenwood, D. (1982). Cultural authenticity. Cultural Survival Quarterly, 6 (3), pp. 27-28.

Grünewald, Rodrigo de Azevedo. (2002). Tourism and cultural revival. Annals of Tourism Research, 29 (4), pp. 1004-1021.

Grünewald, Rodrigo de Azevedo. (2003). Turismo e etnicidade. Horizontes Antropológicos, Porto Alegre, 20, pp. 141-159.

Guanaes, Sandra; Lima, Solange Almeida; Portilho, Wagner Gomes. (2004). Quilombos e usos sustentáveis. In: Diegues, Antonio Carlos; Viana, Virgílio M.. Comunidades tradicionais e manejo de recursos naturais da mata Atlântica. São Paulo: Hucitec: NUPAU: CEC.

Hardin, Garet. (1968). The tragedy of the commons. Science, 162, pp. 1243-1248.

Hernandez Maestro, Rosa M.; Muñoz Gallego, Pablo A.; Santos Requejo, Libia. (2007). The moderating role of familiarity in rural tourism in Spain. Tourism Management, 28, pp. 951-964. 
Houaiss, Antônio E Villar, Mauro de Salles. (2001). Dicionário Houaiss da língua portuguesa. Rio de Janeiro: Objetiva.

ILLICH, Ivan. (1976) . A Convivencialidade. Lisboa: Europa-América.

ILO, International Labour Organization. (1991). Convention concerning indigenous and tribal peoples in Independent Countries. ILO, n. 169, 72 ILO Official Bill, 59, sep. 5, article 1. Basle: ILO.

Irving, M. E Azevedo, J.(2002). Turismo: o desafio da sustentabilidade. São Paulo: Futura.

Kim, Hyounggon; Cheng, Chia-Kuen; O'leary, Joseph T. (2007). Understanding participation patterns and trends in tourism cultural attractions. Tourism Management, 28, pp. 1366-1371.

Kim, Samuel S., Timothy, Dallen J. E Han, Hag-Chin. (2006). Tourism and political ideologies: a case of tourism in North Korea. Tourism Management, 28, pp.1031-1043.

Laarman, J. E Durst, P.(1987). Nature travel and tropical forests. FREI Working Paper Serie. Raleigh, NC, USA: Southeastern Center for Forest Economics Research, North Carolina State University.

Leff, Enrique. (2001). Epistemologia ambiental. São Paulo: Cortez.

Leff, E. (2000). Epistemologia ambiental. São Paulo: Cortez.

Lisboa, A. M. \& Faustino, A. V. (2006). Trocas solidárias, moeda e espiritualidade. In: IV Encontro Internacional de Economia Solidária do NESOL (USP), São Paulo. Anais ..., São Paulo.

Mcgehee, N. G. (2002) Alternative tourism and social movements. Annals of Tourism Research, v. 29, n. 1, pp. 124-143.

Mercer, D. (2002) A difícil relação entre o turismo e a população nativa: a experiência da Austrália. In: Theobald, William F. (Org.). Turismo global. São Paulo: Senac.

Nash, Denninson. (1996) Antropology of tourism. New York: Pergamon.

Oyarzún, Edgardo M.; Carcamo, Carolina Galaz. (Org.). (2001) Analisis de la red agroturismo Chiloé. Facultad de Ciencias Económicas y Administrativas, Instituto de Turismo, Universidad Austral de Chile.

Pagdin, C. (1995) Assessing tourism impacts in the third world. Progress in Planning, v. 44.

Pearce, Philip. (2002) A relação entre residentes e turistas: literatura sobre pesquisas e diretrizes de gestão. In: Theobald, William F. (Org.). Turismo global. São Paulo: Senac.

Plataforma Komyuniti y el Comercio Justo. (2005) Cooperativa Comercio Justo Chile. Disponible em http://www.tiendacomerciojusto.cl/es_que_es_comercio_justo.php. Acesso em 16/jun/ 
PNUD, Programa das Nações Unidas para o Desenvolvimento. Informe sobre desenvolvimento humano 2010. Disponível em http://hdr.undp.org/en/reports/global/hdr2010/chapters/pt/. Acesso em 11 de julho de 2011.

Ryan, Chris. (2002) Tourism and cultural proximity: examples from New Zealand. Annals of Tourism Research, v. 29, n. 4, pp. 952-971.

Sampaio, Carlos Alberto Cioce (Org.).(2010) Gestão que privilegia uma outra economia: ecossocioeconomia das organizações. Blumenau: EDIFURB.

Sampaio, Carlos Alberto Cioce, CARVALHO, Moreno Bona, ALMEIDA, Fernando H. R. de. (2007) Turismo comunitário: projeto piloto montanha beija-flor dourado em uma zona laboratório de educação para o ecodesenvolvimento In: Encontro Nacional de Turismo com Base Local (ENTBL), 2007, João Pessoa (PB). Anais ..., João Pessoa (PB): UFPB.

SAMPAIO, Carlos Alberto Cioce, BERBERI, André E DREHER, Marialva. (2006) Arranjo socioprodutivo local de base comunitária. In: III Encontro da Associação Nacional de Pós-Graduação e Pesquisa em Ambiente e Sociedade (ANPPAS), 2006, Brasília (DF). Anais ..., Brasília.

Sampaio, Carlos Alberto Cioce. (2005) Turismo como fenômeno humano. Santa Cruz do Sul: EDUNISC.

Sampaio, Carlos Alberto Cioce. (2004) El turismo como fenómeno histórico. Estudios y Perspectivas del Turismo, v.13, p. $290-300$.

Schaerer, J..; Dirven, M. (2001) El turismo rural en Chile. CEPAL, Serie Desarrollo Productivo, n. 112.

Scheyvens, Regina. (1999) Ecotourism and the empowerment of local communities. Tourism Management, v. 20, p. 245-249.

Weaver, David B.; Lawton, Laura J. (2007) Twenty years on: the state of contemporary ecotourism research. Tourism Management, v. 28, p. 1168-1179.

WMO, World Meteorological Organization - UNEP, United Nations Environmental Programme. (2007) Intergovernmental panel on climate change. Paris, February. 